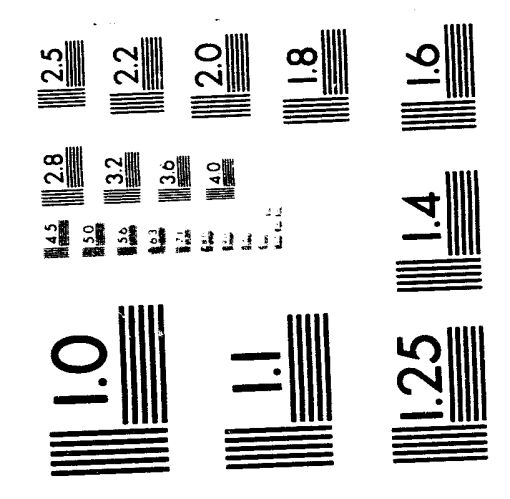



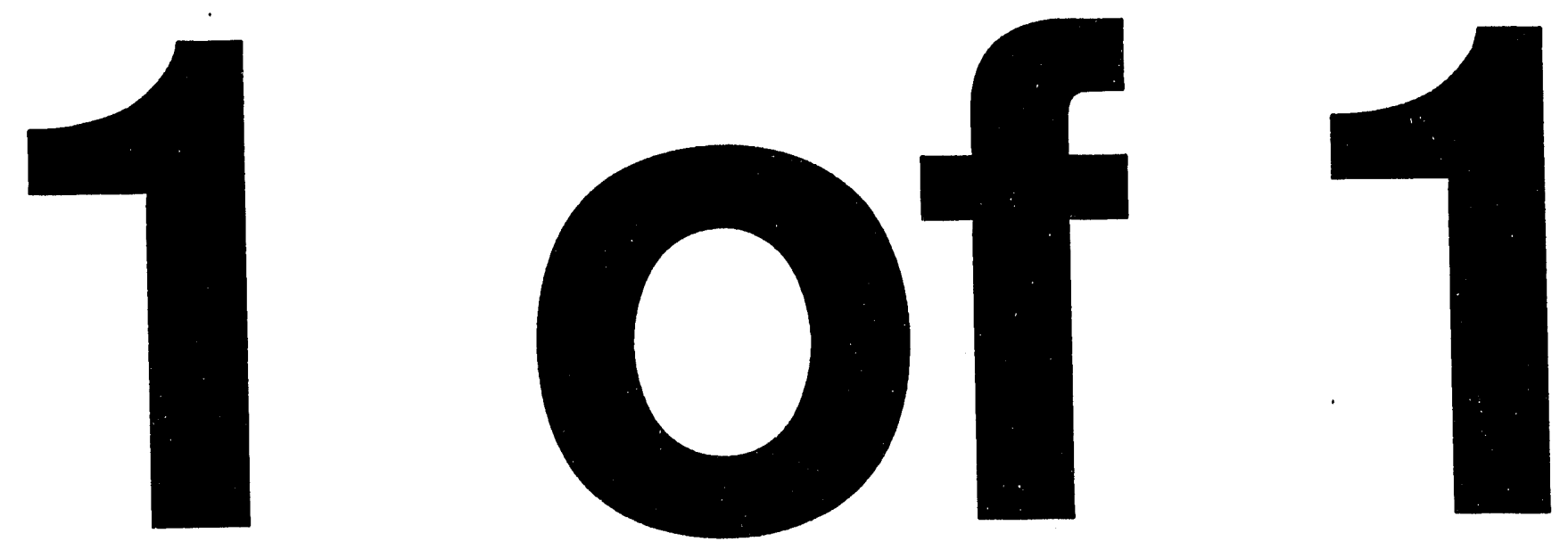


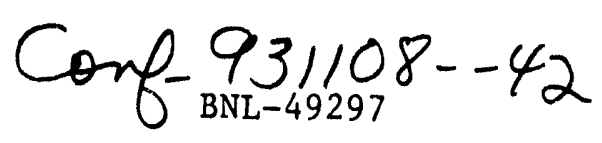

\section{PERFORMANCE OF CVR COATINGS FOR PBR FUELS}

J. W. ADAMS, R. E. BARLETTA, J. SVANDRLIK and P. E. VANIER

Brookhaven National Laboratory, Upton, NY 11973.

\section{ABSTRACT}

As a part of the component development process for the particle bed reactor (PBR), it is necessary to develop coatings for fuel particles which will be time and temperature stable. These coatings must not only protect the particle from attack by the hydrogen coolant, but must also help to maintain the bed in a coolable geometry and mitigate against fission product release. In order to develop these advanced coatings, a process to produce chemical vapor reaction (CVR) coatings on fuel for PBRs has been developed.

The initial screening tests for these coatings consisted of testing in flowing hot hydrogen at one atmosphere. Surrogate fuel particles consisting of pyrolytic graphite coated graphite particles have been heated in flowing hydrogen at constant temperature. The carbon loss from these particles was measured as a function of time. Exposure temperatures ranging from 2500 to $3000 \mathrm{~K}$ were used and samples were exposed for up to 14 minutes in a cyclical fashion, cooling to room temperature between exposures. The rate of weight loss measured as a function of time is compared to that from other tests of coated materials under similar conditions. Microscopic examination of the coatings before and after exposure was also conducted and these results are presented.

\section{INTRODUCTION}

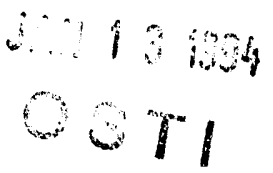

As a part of our continuing studies on the properties of coated carbon composites, a series of investigations has been undertaken on graphite particles which have been coated with refractory carbides by a chemical vapor reaction (CVR) process. The goal of this work is to evaluate the endurance of these coatings in flowing, high temperature hydrogen. The basic substrate for this work was a batch of graphite particles obtained from Superior Graphite, grade number 9400 , identified by the manufacturer as purified spherical graphitic carbon. This substrate was coated with a layer of pyrolytic graphite along with subsequent layers of refractory carbides ( $\mathrm{NbC}$ and $\mathrm{TaC}$ ) by the Advanced Ceramics Corporation. The resultant surrogate fuel particles were then characterized for coating thickness, grain size, free carbon, NbC stoichiometry and surface area. The results of these characterization tests have been previously reported.[1]

Two types of coatings were deposited using the CVR process, NbC coatings and a bilayer coating of $\mathrm{TaC}$ and $\mathrm{NbC}$ with a PG interlayer. For the $\mathrm{NbC}$ coating, three nominal thickness were produced: $8 \mu \mathrm{m}, 25 \mu \mathrm{m}$ and $40 \mu \mathrm{m}$. For the bilayer coating, an initial $8 \mu \mathrm{m}$ of CVR-NbC was placed on the particle, this was followed by $20 \mu \mathrm{m}$ of PG and $10 \mu \mathrm{m}$ of CVR-TaC. The nominal and measured coating thickness for each coating type tested is given in Table 1.1 and a typical cross section of a monolayer coating is shown in Figure 1.

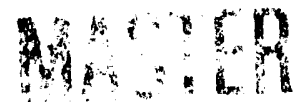


Table I. Characteristics of as-supplied coatings[1]. Coating type and nominal thickness are listed from the particle interior to the exterior.

\begin{tabular}{||l|l|c|c||}
\hline $\begin{array}{c}\text { Batch I.D. } \\
\text { Number }\end{array}$ & Coating Type & $\begin{array}{c}\text { Nominal } \\
\text { Thickness } \\
(\mu \mathrm{m})\end{array}$ & $\begin{array}{c}\text { Measured } \\
\text { Thickness } \\
(\mu \mathrm{m})\end{array}$ \\
\hline 1P100491 & PG/NbC & $35 / 8$ & $9.8 \pm 0.6$ \\
\hline $1 \mathrm{P} 121291$ & $\mathrm{PG} / \mathrm{NbC}$ & $25 / 25$ & $24.5 \pm 1.4$ \\
\hline $1 \mathrm{P} 011092$ & $\mathrm{PG} / \mathrm{NbC}$ & $5 / 40$ & $41.1 \pm 2.8$ \\
\hline $1 \mathrm{P} 041092$ & $\mathrm{NbC} / \mathrm{PG} / \mathrm{TaC}$ & $8 / 50 / 10$ & $8.0 \pm 2.2(\mathrm{NbC})$ \\
& & & $54.6 \pm 6.9(\mathrm{PG})$ \\
& & $12.6 \pm 1.3(\mathrm{TaC})$ \\
\hline
\end{tabular}

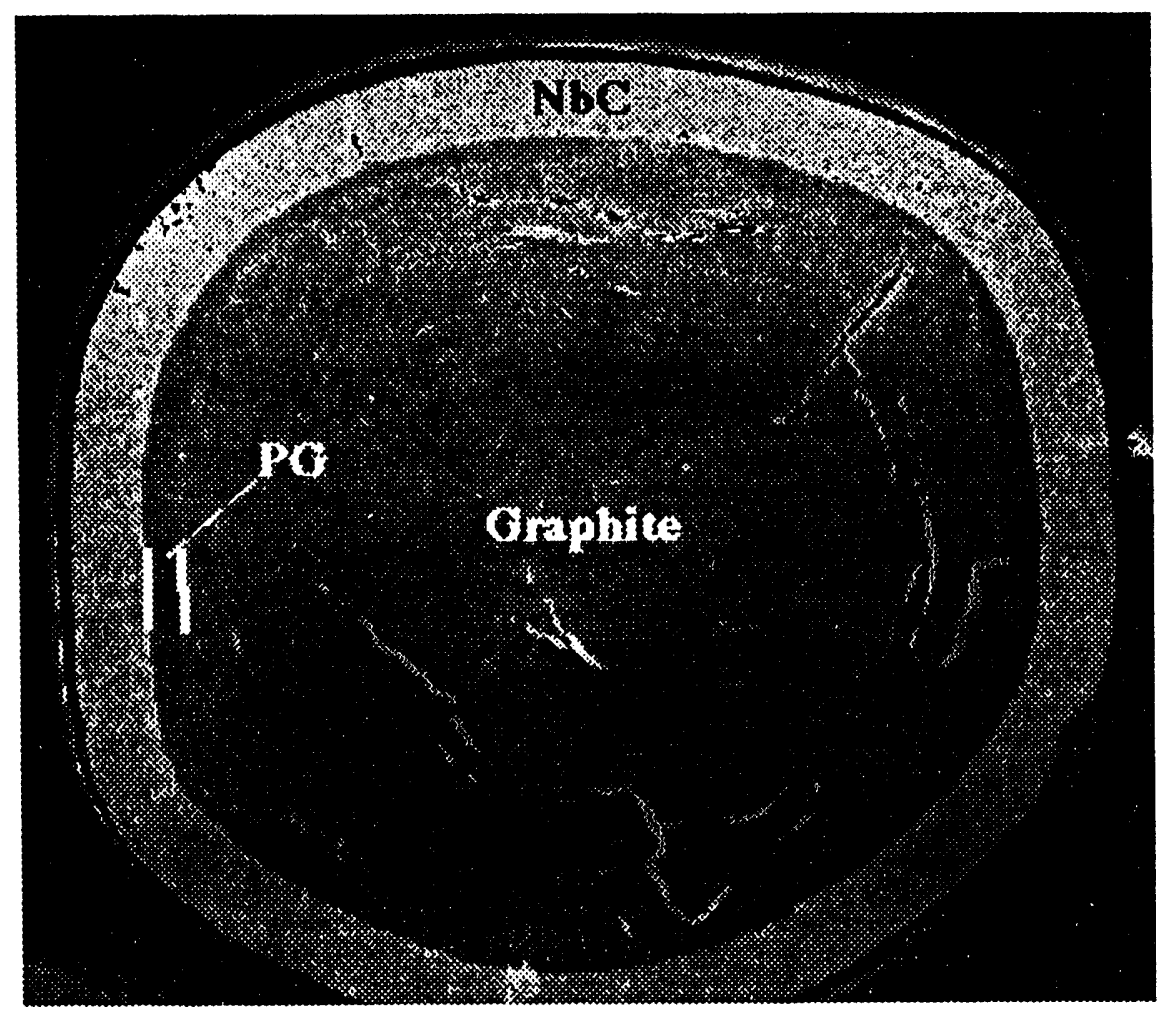

Figure 1. Typical cross section of nominal $40 \mu \mathrm{m}$ coating at $150 \mathrm{X}$.

\section{EXPERIMENTAL}

The basic experimental procedure used for hot $\mathrm{H}_{2}$ testing has been previously described.[2] Heating was performed in an induction furnace with a TaC-coated graphite susceptor in $\mathrm{H}_{2}$ at ambient pressure flowing at $300 \mathrm{std}$. $\mathrm{cm}^{3} / \mathrm{min}$. A weighed amount of particles was placed inside the susceptor in a weighed $\mathrm{TaC}$ carbide-coated graphite crucible. The test temperature ranged from 2400 to $3200 \mathrm{~K}$ for a duration of 1 to 3 minutes. After heating, the sample was cooled under flowing He. Weight loss from the particles was determined by difference of the pre- and post-test weights allowing for the weight loss by the crucible. Three to five such cycles were performed for each test series. Multiple weighings of each sample were taken and the results averaged to give a weight at the completion of a cycle. Variations in weight of a few tenths of a milligram were 
common in the weighings. Post-heat BET surface area measurements were made on $40 \mu \mathrm{m} \mathrm{NbC}$ particles by Quantchrome Corporation using a multipoint surface area measurement with $\mathrm{Kr}$ gas.

\section{RESULTS}

The incremental and cumulative weight loss from each of the four coating types was expressed as percentage of the available carbon in the as-received particles using the free carbon data from [1]. Weight loss was plotted as a function of time for each test temperature as shown in Figure 2 for bilayer particles. The data showed a linear dependence of the amount of weight lost as function of time. The slopes and intercepts of the regression lines for each data set are listed in Table II.

A large number of samples of the $40 \mu \mathrm{m} \mathrm{NbC}$ coated material were heated cyclically at $2800 \mathrm{~K}$ in $\sim 0.5$ gram batches in order to obtain enough material for surface area determination. The weight loss following these tests was found to be $8.39 \pm 1.13 \%$ of the available carbon and the post-heating surface area was $4.915 \times 10^{-2} \mathrm{~m}^{2} / \mathrm{g}$.

\section{DISCUSSION}

Table II shows a large sample-to-sample variation in the weight loss data at a given temperature. This is most likely due to variations in the coated graphite susceptor used to run the experiments. With use, the susceptor becomes more leaky and itself reacts with hydrogen. Thus, the sample sees less than one atmosphere of hydrogen as well as hydrogen which contains the products of reaction with hydrogen. Both these conditions result in a less than maximum sample weight loss. The susceptor was changed when an obvious ill fit between parts or reaction (i.e. spalling) was observed but this does not preclude more subtle degradation from going unnoticed. It was not possible to run the large number of samples at each temperature and for each coating type. Thus, results can only be used to provide at best a semi-quantitative comparison among coating types.

The rate data obtained shows a simple Arrhenius behavior when plotted as a function of temperature. Figure 3 shows the results of an exponential curve fit to the rate data plotted against the reciprocal of temperature for each coating type tested. Except for the bilayer coating, the data points have been omitted for clarity. In addition, rate data for $\mathrm{ZrC}$ coated prototype PBR fuel is plotted in this figure. This material was coated using a CVD process. The slopes (activation energies) of the $40 \mu \mathrm{m} \mathrm{NbC}$, bilayer, and $\mathrm{ZrC}$-coated fuel data ( 230 to $250 \mathrm{~kJ} / \mathrm{mole}$ ) are similar to other measurements made on other coated and uncoated carbon (Table III) implying a similar mechanism for reaction. For temperatures above $2500 \mathrm{~K}$, the CVR coatings are superior to the CVD coatings even for the thinnest CVR coating. Further, dramatic improvements in performance can be obtained by increased coating thickness. Bilayer coatings show the best performance with almost an order of magnitude lower rate of weight loss than the CVD coating between 2600 and $3000 \mathrm{~K}$.

Several factors may account for these results. First, the reaction rate is almost certainly surface area dependent. BET surface areas for unheated samples indicated that the bilayer particles had a much lower available surface area than even the $40 \mu \mathrm{m} \mathrm{NbC}$. Second, preliminary analysis of the data indicates a correlation of the phenomenological rate of weight loss with the coating grain size for the CVR coatings.[3] Finally, CVD coatings have been found to show large changes in morphology after heating which can affect the performance of CVD coated carbons in $\mathrm{H}_{2}$. [4] Microscopic examination of CVR coatings after heating showed no obvious morphological 
changes, and post-heating measurement of BET surface area for the $40 \mu \mathrm{m} \mathrm{NbC}$ particles showed only a slight $(-10 \%)$ decrease in the surface area with heating.

Table II. Slope and intercepts for least squares fits of weight loss data.

\begin{tabular}{|c|c|c|c|}
\hline $\begin{array}{c}\text { Slope } \\
\text { (\% Avail. C /second) }\end{array}$ & $\begin{array}{c}\text { Intercept } \\
\text { (\% Avail. C) }\end{array}$ & $\begin{array}{c}\text { Temperature } \\
(\mathrm{K})\end{array}$ & Comments \\
\hline $\begin{array}{c}10 \mu \mathrm{m} \mathrm{NbC} \\
0.00845 \\
0.0277 \\
0.0131 \\
0.0164 \\
0.0270 \\
0.0334 \\
25 \mu \mathrm{m} \mathrm{NbC} \\
0.0110 \\
0.0170 \\
0.0358 \\
40 \mu \mathrm{m} \mathrm{NbC} \\
0.00182 \\
0.00516 \\
0.00723 \\
0.00638 \\
0.0193 \\
0.0204 \\
0.0159 \\
0.0429 \\
\text { Bilayer } \\
0.00205 \\
0.00259 \\
0.00726 \\
0.0203\end{array}$ & $\begin{array}{c}-0.232 \\
3.118 \\
0.454 \\
0.764 \\
0.679 \\
0.131 \\
\\
0.741 \\
0.533 \\
1.038 \\
-0.0235 \\
0.240 \\
0.124 \\
0.434 \\
-0.319 \\
0.6823 \\
0.578 \\
1.954 \\
\\
-0.0894 \\
-0.253 \\
0.526 \\
-0.00865\end{array}$ & $\begin{array}{l}2500 \\
2600 \\
2600 \\
2800 \\
2800 \\
3000 \\
\\
2500 \\
2800 \\
3000 \\
\\
2500 \\
2500 \\
2500 \\
2800 \\
2800 \\
2800 \\
3000 \\
3200 \\
2400 \\
2600 \\
2800 \\
3000\end{array}$ & $\begin{array}{l}\text { Run 1 } \\
\text { Run 2 } \\
\text { Run 3 } \\
\text { Run 1 } \\
\text { Run 2 } \\
\text { Run 3 }\end{array}$ \\
\hline
\end{tabular}

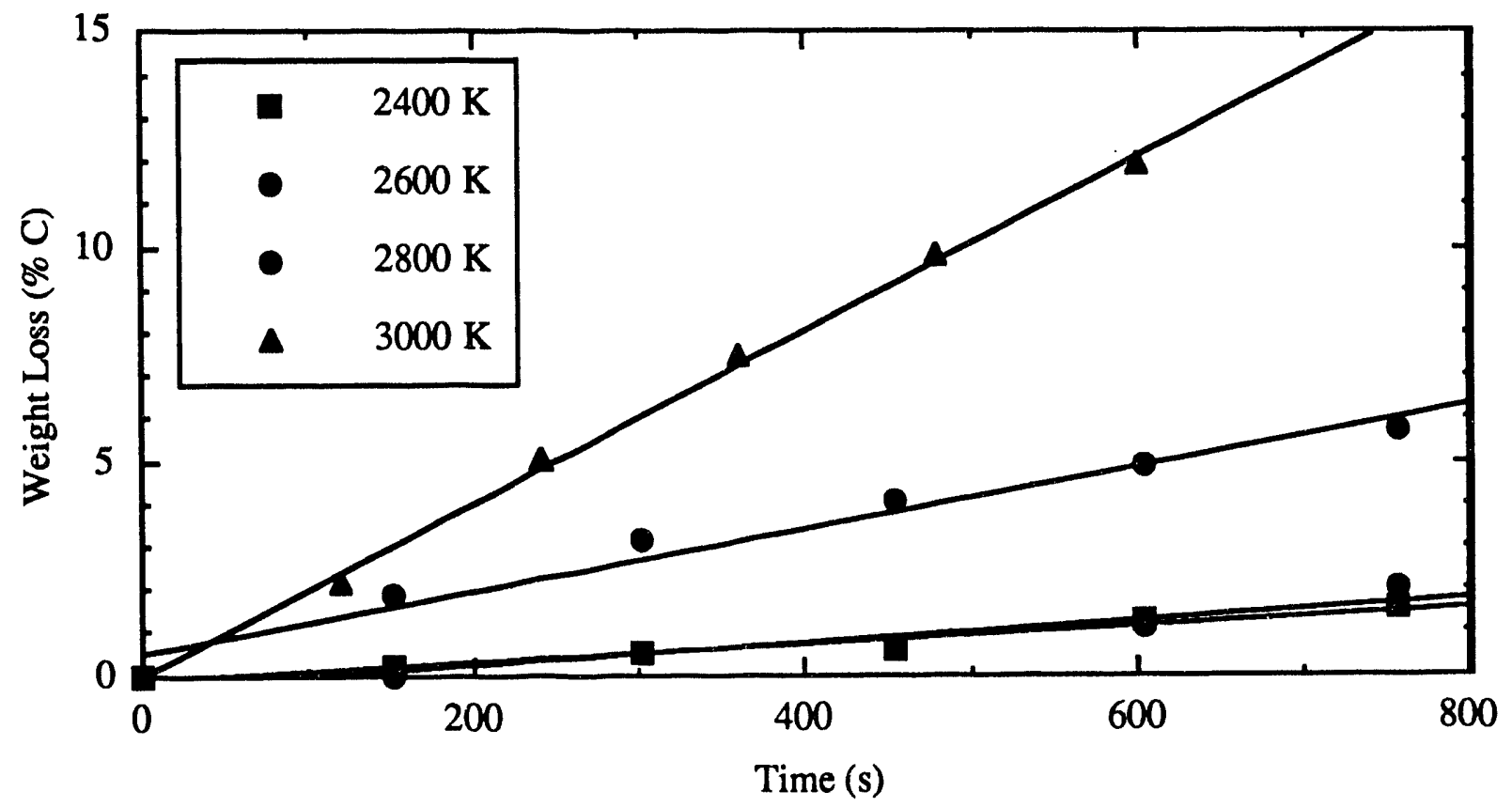

Figure 2. Weight loss versus time for bilayer coating in hydrogen. 


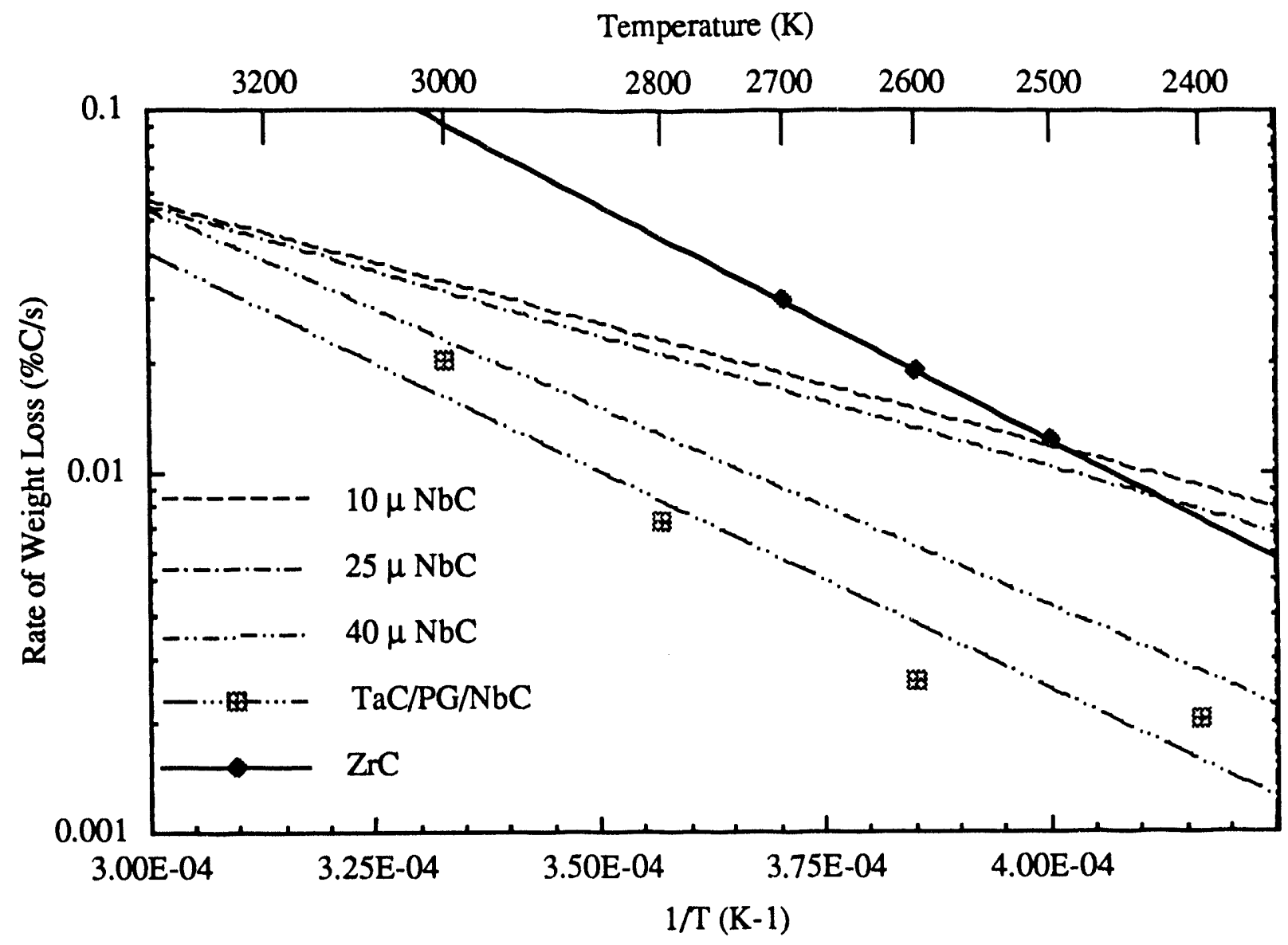

Figure 3. Arrhenius plot of the rate of carbon loss from CVR-coated graphite particles and $\mathrm{ZrC}$ coated prototype fuel.

Table III. Activation energies, $\mathrm{E}_{\mathrm{a}}$, for the reaction of $\mathrm{H}_{2}$ with various coated and uncoated carbons

\begin{tabular}{|l|c|c|c||}
\hline Coating/Substrate & $\begin{array}{c}\mathrm{E}_{\mathrm{a}} \\
(\mathrm{kcal})\end{array}$ & $\begin{array}{c}\mathrm{E}_{\mathrm{a}} \\
(\mathrm{kJ})\end{array}$ & Reference \\
\hline $10 \mu \mathrm{NbC/particle}$ & 31 & 130 & - \\
$25 \mu \mathrm{NbC/particle}$ & 33 & 140 & - \\
$40 \mu \mathrm{NbC/particle}$ & 50 & 210 & - \\
Bilayer/particle & 55 & 230 & - \\
CVD ZrC/fuel & 60 & 250 & - \\
TaC/2D C-C & 80 & 340 & 5 \\
TaC/3D C-C & 77 & 320 & 5 \\
TaC/Graphite & 70 & 290 & 5 \\
none/graphite & 54 & 230 & 5 \\
none/graphite & 51 & 210 & 6 \\
\hline
\end{tabular}




\section{CONCLUSIONS}

The development work reported herein demonstrates the practicality of CVR coatings of refractory carbides to fuel particles for PBR reactors in which an underlying layer of carbon is tolerable. This layer is necessary to provide the carbon for carbide formation. These coatings provide performance in hydrogen superior to similar coatings applied using CVD processes when tested to $3000 \mathrm{~K}$.

The CVR coating development work and the testing conducted thusfar have been extremely limited. Further improvements in coating performance might well be realized with additional effort. These tests indicate the potential of multi-layer coatings for achieving high performance coatings. Much more work is also needed in this area to optimize variables such as the number, type and thickness of the layers used. In particular, thin layers of $\mathrm{TaC}$ appear to be very good at providing hydrogen protection. These experiments provide little information regarding reaction rates under prototypic PBR conditions. The effects of radiation, thermal cycling, hydrogen flow rate and pressure must also be measured. Finally, with respect to overall fuel performance, the ability of such coatings to aid in fission product retention should be evaluated.

\section{ACKNOWLEDGMENTS}

Research performed under funding provided by the US Air Force's Philipps Laboratory Space Nuclear Thermal Propulsion Program, Proposal No. PL-STX-92-006.

\section{REFERENCES}

1. R. E. Barletta, P. E. Vanier, M. B. Dowell and J. A. Lennartz, "The Development of CVR Coatings for PBR Fuels", Paper N.9.6 this symposium .

2. R. E. Barletta, P. E.,Vanier, J. W., Adams and J. F. Svandrlik, "Carbon Erosion in Hydrogen - The "Midband" Problem Revisited", Tenth Symposium on Space Nuclear Power and Propulsion, M. S. El-Genk and M. D. Hoover, eds., AIP Conference Proceedings 271, CONF930103,1993, p 245.

3. M. Dowell, Advanced Ceramics Corporation, private communication.

4. J. W. Adams, R. E. Barletta, J. Svandrlik and P. E. Vanier, "Performance of CVD and CVR Coated Carbon-Carbon in High Temperature Hydrogen", Paper N 4.3 in this symposium.

5. R. E. Barletta, P. E.,Vanier, J. W., Adams, J. F. Svandriik and J. R. Powell, "Performance of Carbon Based Hot Frit Substrates. 2. Coating Performance Studies in Hydrogen at Atmospheric Pressure", BNL Informal Report, BNL-49385, 1993.

6. J. T. Clarke and R. R. Fox, J. Chem. Phys., 46, 827 (1967).

\section{DISCLAIMER}

This report was prepared as an account of work sponsored by an agency of the United States Government. Neither the United States Government nor any agency thereof, nor any of their employees, makes any warranty, express or implied, or assumes any legal liability or responsibility for the accuracy, completeness, or usefulness of any information, apparatus, product, or process disclosed, or represents that its use would not infringe privately owned rights. Reference herein to any specific commercial product, process, or service by trade name, trademark, manufacturer, or otherwise does not necessarily constitute or imply its endorsement, recommendation, or favoring by the United States Government or any agency thereof. The views and opinions of authors expressed herein do not necessarily state or reflect those of the United States Government or any agency thereof. 

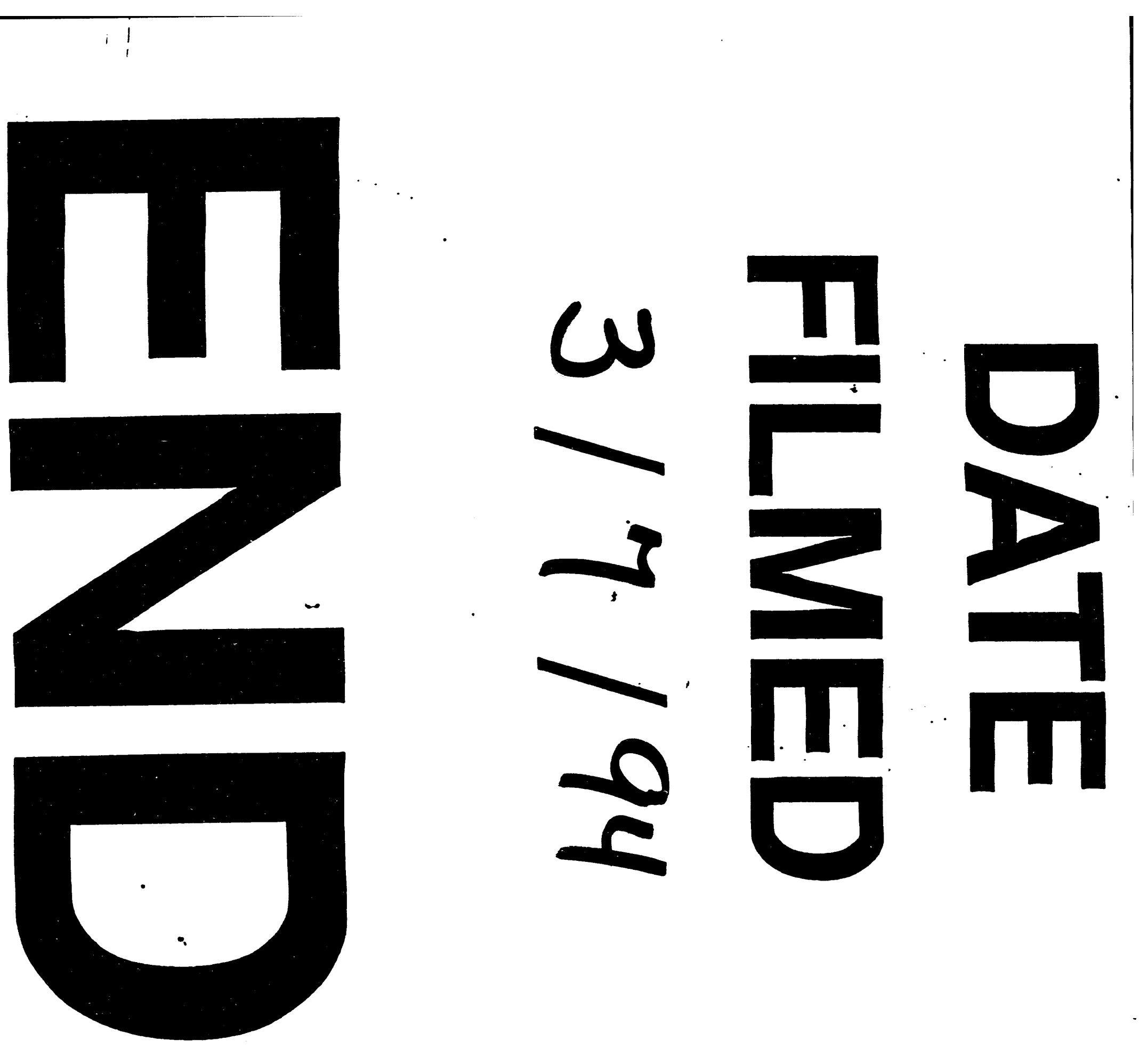
